\title{
Rancangbangun Alat Sinkronisasi Generator Berbasis Mikrokontroler
}

\author{
Atika Endefi ${ }^{1}$, Sukardi $^{2}$ \\ ${ }^{1}$ Universitas Negeri Padang \\ Jl. Prof Dr. Hamka Air Tawar, Padang Indonesia \\ aendefi@gmail.com ${ }^{1}$, sukardiunp@gmail.com²
}

\begin{abstract}
Synchronization is one way to get great electrical energy from the generator by parsing it. The terms of the generator synchronization are the frequency value, phase angle, sequence of phases and voltage must be the same or in accordance with the specified conditions, where the tolerance of different phase angles is 10 degrees and the resulting voltage range is 49 Volts. This synchronization is used by two generators where generator 1 (main) is considered a set point that will be adjusted by generator 2 (parallel) to equalize the value of synchronization terms. In voltage tanning, a boost converter method is used which is a type of DC-DC converter that raises dc voltage through PWM settings. For the control system, the controller used is the Arduino Mega2560 which will display the generator requirement value 2 (parallel) with generator 1 (main) on the LCD. For phase angles, the tool will auto-adjust by repeating the generator's livelihood with close loop control until it gets the same phase angle value. If the synchronization requirement values of both generators are the same, the controller will enable the contactor so that the generator synchronization occurs. When experiments are conducted, based on the research stages and data from the experiment can be concluded that the tool successfully works in accordance with the research objectives.
\end{abstract}

Keywords - Synchronization Generator, Boost Converter, Close Loop, Microcontroller.

\begin{abstract}
Abstrak-Sinkronisasi merupakan salah satu cara untuk mendapatkan energi listrik yang besar dari generator dengan cara memparalelkannya. Adapun syarat dari sinkronisasi generator adalah nilai frekuensi, sudut fasa, urutan fasa-fasa dan tegangan harus sama atau sesuai dengan syarat ketentuan yang ditentukan, yang mana toleransi beda sudut fasa adalah 10 derajat dan beda tegangan yang dihasilkan kisaran 49 Volt. Sinkronisasi ini digunakan dua buah generator yang mana generator 1 (utama) dianggap sebagai set point yang akan disesuaikan oleh generator 2 (parallel) untuk menyamakan nilai syarat sinkronisasi. Dalam penyamaan tegangan, digunakan metode boost converter yang merupakan jenis $D C$-DC converter yang menaikkan tegangan DC melalui pengaturan PWM. Untuk sistem kendalinya, kontroller yang digunakan adalah Arduino Mega2560 yang akan menampilkan nilai syarat generator 2 (paralel) dengan generator 1(utama) pada LCD. Untuk sudut fasa, alat akan menyesuaikan otomatis dengan cara mengulang penghidupan generator dengan kendali close loop hingga di dapatkan nilai sudut fasa yang sama. Jika nilai syarat sinkronisasi kedua generator sama, kontroller akan mengaktifkan kontaktor sehingga terjadi sinkronisasi generator. Saat dilakukan percobaan, berdasarkan tahap-tahap penelitian dan data dari percobaan dapat disimpulkan bahwa alat berhasil bekerja sesuai dengan tujuan penelitian.
\end{abstract}

Kata kunci-Sinkronisasi Generator, Boost Converter, Close Loop, Mikrokontroler.

\section{Pendahuluan}

Kebutuhan energi listrik semakin meningkat di Indonesia dan energi listrik sudah menjadi bagian utama hampir disetiap kehidupan masyarakat saat ini seiring dengan semakin berkembangnya bidang teknologi dan industri[1]. Setiap tahunnya, terjadi peningkatan konsumsi energi listrik baik dari sektor rumah tangga maupun industri[1][2]. Untuk memenuhi kebutuhan energi listrik tersebut memerlukan pembangkit listrik yang banyak dan pembangkit listrik umumnya menggunakan generator sebagai sumber penghasil listrik, baik itu generator uap, gas, air dan tenaga diesel[3]. Generator bisa dimanfaatkan untuk menghasilkan energi listrik yang lebih besar, salah satunya dengan melakukan metode sinkronisasi generator[3]. Adapun syarat yang harus diperhatikan dalam sinkronisasi generator adalah kesamaan nilai tegangan, frekuensi, beda sudut fasa dan urutan fasa-fasanya[4].

Boost converter merupakan salah satu converter yang banyak digunakan dalam mengubah tegangan DC menjadi lebih tinggi dengan menaikkan tegangan [5]. karena merupakan salah stau metode untuk menaikkan tegangan eksitasi yang nilai tegangannya lebih besar dari tegangan masukkan. besar tegangan eksitasi ini bisa diatur sesuai kebutuhan dengan merubah range pulsa PWM (duty cycle)[5].

Boost Converter merupakan salah satu rangkaian elektronika converter DC-DC yang memiliki fungsi menaikkan tegangan atau tegangan keluarannya lebih besar daripada masukannya[5][6]. Boost Converter bekerja dalam dua mode, yaitu yang pertama saat MOSFET dalam keadaan off, yangmana tegangan induktor sama dengan tegangan masukan dan yang kedua saat MOSFET dalam 
keadaan on, arus berkurang dan impedansi lebih tinggi sehingga perubahan ditahan induktor[7].

Sensor frekuensi merupakan sensor yang mendeteksi adanya perubahan pada frekuensi fasa generator. Pada sensor frekuensi digunakan LM358 yang dirancangan dengan op-amp ganda yangmana tidak membutuhkan penggantian frekuensi dan rendahnya noise[8].

Sensor sudut fasa merupakan sensor yang mendeteksi perubahan fasa pada kedua generator. Sensor ini akan melihat ada atau tidaknya beda fasa antara dua tegangan generator. prinsipnya adalah keluaran akan bernilai high jika ada perbedaan logika pada masukanmasukannya yang akan menghasilkan sinyal kotak menjadi representasi beda fasa antara dua generator[9].

Penelitian mengenai Sinkronisasi generator sudah dilakukan sebelumnya oleh Tri Prasetya, Yahya C., dan Suhariningsih. Dari hasil penelitian tersebut, penyamaan tegangan masih dilakukan secara manual dan kontrollernya menggunakan PLC Zelio[10].
Selain penelitian diatas, penelitian lain umumnya, sinkronisasi generator dilakukan secara manual setelah memenuhi syarat-syaratnya, yaitu : Tegangan, Urutan fasa, Sudut fasa, dan frekeunsi. Akan tetapi, yang sering didapati dilapangan adalah perbedaan tegangan generator yang akan disinkronkan tidak sama. untuk itu, pada alat ini ditambahkan mikrokontroler untuk menggunakan metode boost converter dengan kendali close loop untuk menyamakan syarat sinkronisasi antara kedua generator.

\section{Metode}

Pada bab metode ini akan membahas tentang perancangan hardware dan software dari alat.

\section{A. Blok Diagram}

Merupakan penjelasan singkat dari sistem kontrol alat yang terdiri dari sejumlah komponen yang terhubung dan menjalankan fungsi yang diinginkan, yangmana dijelaskan singkat dalam serangkaian blok-blok yang dihubungkan oleh garis-garis panah.

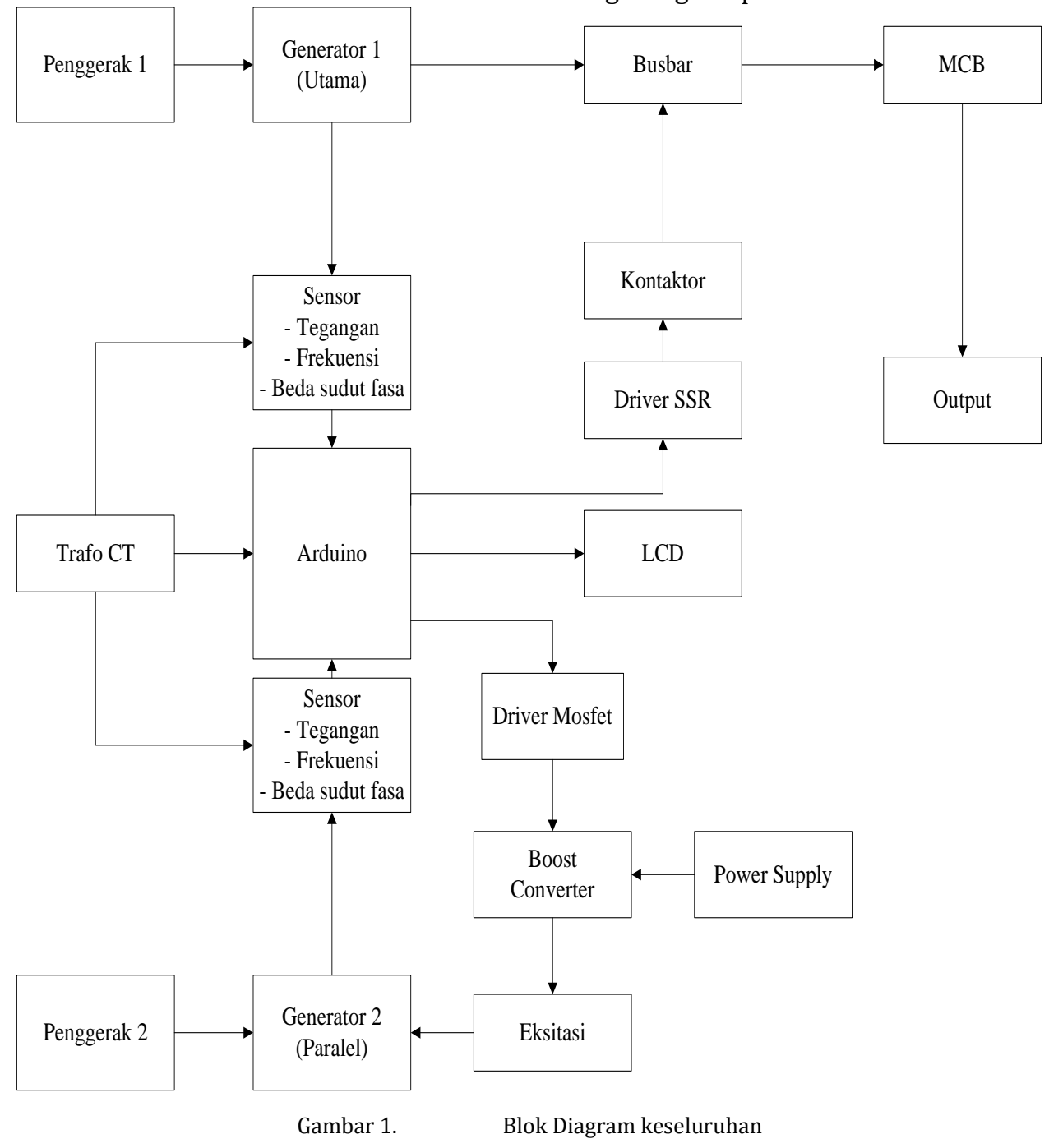


Berdasarkan Gambar 1, dapat dijelaskan komponenkomponen penyusunnya sebagai berikut:

1. Penggerak, berfungsi sebagai sumber energi mekanik agar generator dapat berputar. Penggerak yang digunakan dalam penelitian adalah motor.

2. Generator, sebagai objek yang akan dilakukan penelitian sistem sinkronisasi.

3. Sensor tegangan, berfungsi untuk mendeteksi besarnya tegangan keluaran pada generator.

4. Sensor Frekuensi, berfungsi mendeteksi besaran frekuensi dalam perioda.

5. Sensor sudut fasa untuk mendeteksi perbedaan sudut fasa.

6. Arduino Mega2560, berfungsi sebagai controller pusat sistem.Kontaktor, berfungsi sebagai penyambung dan pemutus

7. Kontaktor, berfungsi untuk

8. MCB, sebagai pengaman dalam sistem sinkronisasi.

9. LCD display, untuk penampil data.

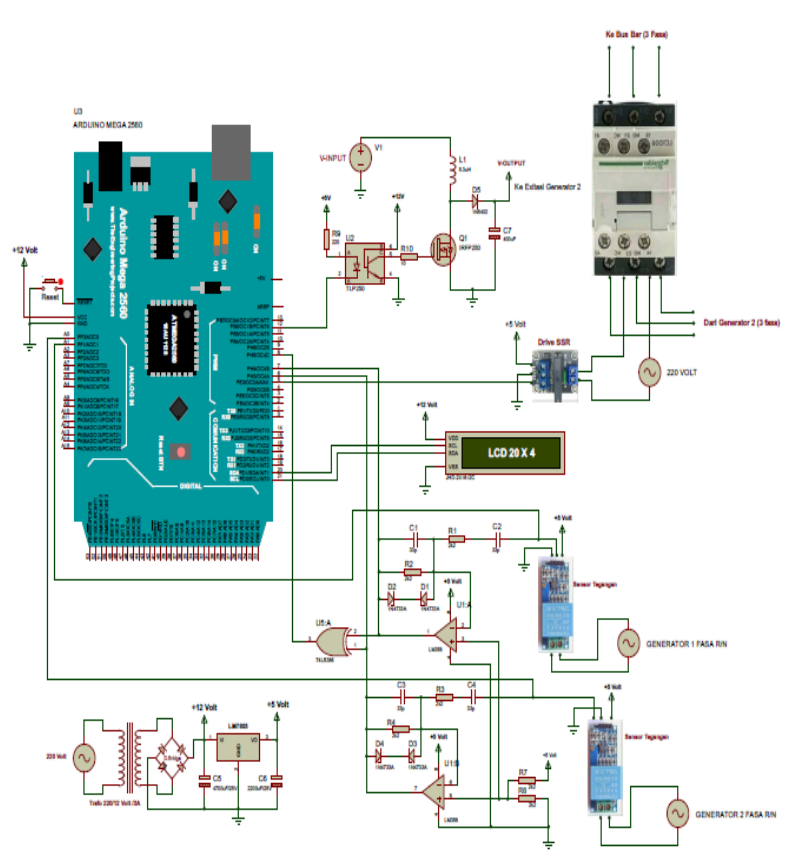

Gambar 2.

Rangkaian Keseluruhan

\section{B. Perancangan Mekanik alat}

Peracangan mekanik merupakan suatu proses atau tahapaan dalam pembuatan tugas akhir untuk dapat diuji secara nyata.

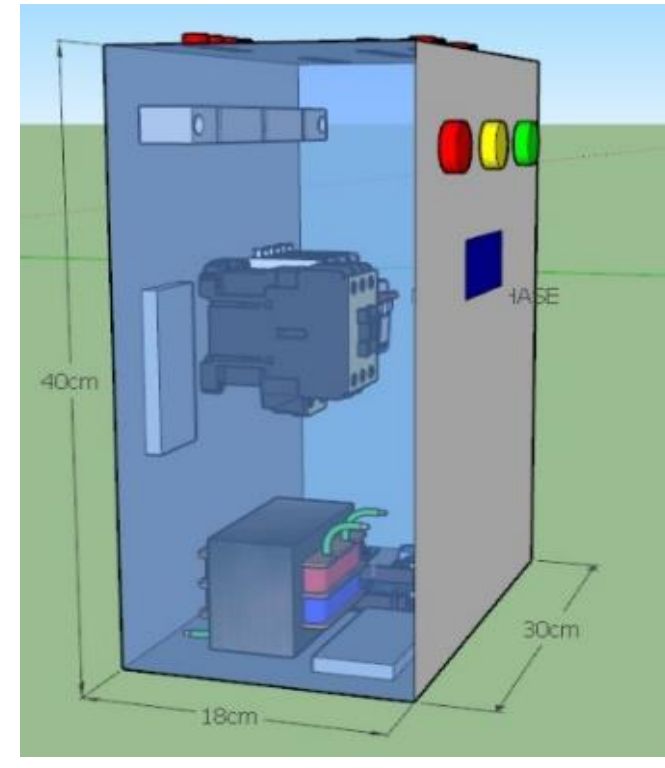

Gambar 3. Perancangan Mekanik

\section{Flowchart}

Flowchart merupakan penjelasan logika atau instruksi bagaimana cara kerja alat sinkronisasi generator, yang dapat dilihat pada gambar 4.

Adapun prinsip kerja alat pada rancangbangun alat sinkronisasi generator berbasis mikrokontoler yang pertama dilakukan adalah melakukan pengecekan pada urutan fasa kedua generator. Setelah urutannya sama, alat dihidupkan dengan memberikan tegangan sumber. Berikutnya, generator 1 dihidupkan hingga mencapai nilai tegangan masukan motor tertentu dan melihat nilai pembacaan sensor pada LCD. Lalu generator 2 diberikan tegangan input boost converter dan hidupkan generator 2 dengan memberikan input motor yang sama dengan input motor generator 1. Mikrokontroller berikutnya akan membaca nilai syarat-syarat kedua generator, jika nilai tegangannya tidak sama, mikrokontroler akan menambah nilai PWM sehingga eksitasinya naik. Berikutnya mikrokontroler akan mengecek syarat-syarat sinkronisasi kedua generator sebanyak 10 kali. Jika sudah terpenuhi, kontaktor akan diaktifkan sehingga terjadi sinkronisasi pada kedua generator. 


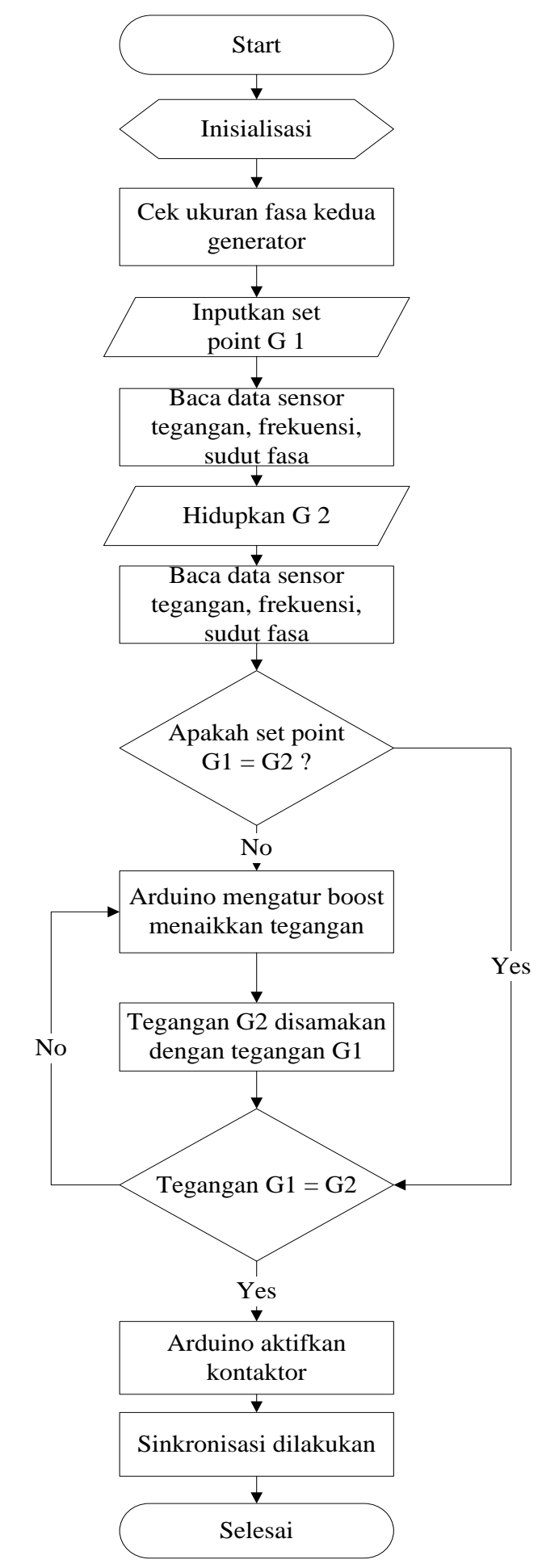

Gambar 4.

Flowchart Sinkronisasi Generator

\section{HASIL DAN PEMBaHASAN}

Pada hasil dan pembahasan, akan dilakukan beberapa pegujian dan analisa pada bagian input dan output. Pengujian dan analisa ini bertujuan untuk mengetahui terhadap kinerja keberhasilan alat dalam pengujian nyata. Bentuk mekanik alat dapat dilihat pada gambar 5 :

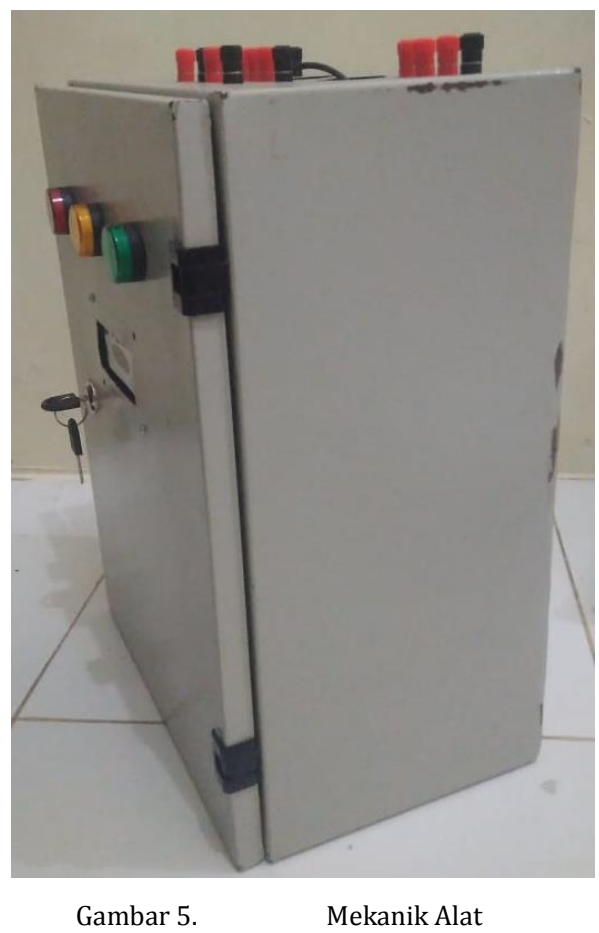

\section{Pengujian Alat pada Generator 1}

Pengujian ini dilakukan untuk membandingkan hasil dari pembacaan sensor alat dengan peralatan ukur manual yangmana nilai eksitasi 90 Volt, Arus Eksitasi 0,6 A.

TABEL I. PENGUJIAN PADA GENERATOR 1

\begin{tabular}{|c|c|c|c|c|c|}
\hline No & $\begin{array}{l}\text { Input } \\
\text { Motor }\end{array}$ & $\begin{array}{c}\text { Tegangan } \\
\text { Sensor }\end{array}$ & $\begin{array}{l}\text { Tegangan } \\
\text { Alat Ukur }\end{array}$ & $\begin{array}{c}\text { Frekuensi } \\
\text { Sensor }\end{array}$ & $\begin{array}{l}\text { Frekuensi } \\
\text { Alat Ukur }\end{array}$ \\
\hline 1 & 50 Volt & 30 Volt & 24 Volt & $-40,6 \mathrm{~Hz}$ & $17,22 \mathrm{~Hz}$ \\
\hline 2 & $\begin{array}{l}100 \\
\text { Volt }\end{array}$ & 45 Volt & 55 Volt & $-41,11 \mathrm{~Hz}$ & $23,89 \mathrm{~Hz}$ \\
\hline 3 & $\begin{array}{l}150 \\
\text { Volt }\end{array}$ & 79 Volt & 80 Volt & $36,1 \mathrm{~Hz}$ & $35,8 \mathrm{~Hz}$ \\
\hline 4 & $\begin{array}{l}190 \\
\text { Volt }\end{array}$ & 101 Volt & 101 Volt & $45,6 \mathrm{~Hz}$ & $45,6 \mathrm{~Hz}$ \\
\hline 5 & $\begin{array}{l}200 \\
\text { Volt }\end{array}$ & 108 Volt & 109 Volt & $48,2 \mathrm{~Hz}$ & $48,19 \mathrm{~Hz}$ \\
\hline
\end{tabular}

Pada tabel 1, menunjukkan hasil pengukuran jika motor diberikan kisaran 50-100 Volt, terdapat error pada alat jika dibandingkan dengan pengukuran hasil dari alat ukur. Begitupun dengan frekuensinya, pembacaan frekuensi alat dengan memiliki perbedaan dengan nilai dari alat ukur. Pembacaan Frekuensi pada alat mulai stabil saat nilai tegangan input motor diberi 150 Volt. Begitupun dengan sensor, nilai pembacaan dari alat mulai sama dengan nilai pembacaan pada alat ukur ketika tegangan motor 
diberikan 190 Volt. Error ini terjadi karena range ukur dari sensor-sensor.

\section{Pengujian Alat pada Generator 2}

TABEL II. PENGUJIAN GENERATOR 2

\begin{tabular}{cccccc}
\hline No & RPM & $\begin{array}{c}\text { Input } \\
\text { Motor }\end{array}$ & $\begin{array}{c}\text { Tegangan } \\
\text { Generator }\end{array}$ & $\begin{array}{c}\text { Tegangan } \\
\text { Eksitasi }\end{array}$ & $\begin{array}{c}\text { Tegangan } \\
\text { masukan } \\
\text { boost }\end{array}$ \\
\hline 1 & 300 & 50 Volt & 40 Volt & 170 Volt & 30 Volt \\
\hline 2 & 450 & 75 Volt & 50 Volt & 170 Volt & 30 Volt \\
\hline 3 & 700 & 100 Volt & 60 Volt & 170 Volt & 30 Volt \\
\hline 4 & 900 & 150 Volt & 90 Volt & 170 Volt & 30 Volt \\
\hline 5 & 1200 & 200 Volt & 125 Volt & 170 Volt & 30 Volt \\
\hline 6 & 1300 & 210 Volt & 130 Volt & 170 Volt & 30 Volt \\
\hline
\end{tabular}

Berdasarkan hasil pengujian dari tabel 2, dapat dilihat bahwa boost converter bekerja dengan baik karena menghasilkan tegangan output yang lebih besar daripada tegangan input. Selain itu, dapat disimpulkan juga bahwa boost converter dapat memberikan eksitasi pada generator.

\section{Pengujian Sinkronisasi}

TABEL III. HASIL PENGUJIAN SINKRONISASI

\begin{tabular}{|c|c|c|c|c|c|c|c|c|}
\hline \multirow[t]{2}{*}{ No. } & \multirow[t]{2}{*}{ VinM } & \multicolumn{2}{|c|}{ G1 } & \multicolumn{2}{|c|}{ G2 } & \multirow{2}{*}{$\begin{array}{c}\boldsymbol{\Phi} \\
1.0 \\
\end{array}$} & \multirow[t]{2}{*}{ Time } & \multirow[t]{2}{*}{ Sinkron } \\
\hline & & V & $\mathrm{Hz}$ & $\mathbf{V}$ & $\mathrm{Hz}$ & & & \\
\hline 1 & 50 & - & -46 & - & -45 & 1.0 & - & Tidak \\
\hline 2 & 100 & 22 & -40 & 22 & -39 & 1.0 & $4 \mathrm{~s}$ & Ya \\
\hline 3 & 150 & 40 & 36 & 40 & 36 & 1.0 & $2 \mathrm{~s}$ & Ya \\
\hline 4 & 200 & 59 & 49 & 59 & 49 & 1.0 & $3 \mathrm{~s}$ & Ya \\
\hline \multicolumn{9}{|c|}{ Keterangan : } \\
\hline V & \multicolumn{8}{|c|}{ = Tegangan } \\
\hline $\mathrm{Hz}$ & \multicolumn{8}{|c|}{ = Frekuensi } \\
\hline VinM & \multicolumn{8}{|c|}{$=$ Tegangan input Motor } \\
\hline$\Phi$ & \multicolumn{8}{|c|}{$=$ Sudut fasa } \\
\hline Time & \multicolumn{8}{|c|}{ = Waktu } \\
\hline
\end{tabular}

Berdasarkan tabel 3, sinkronisasi kedua generator berhasil dilakukan dengan sangat baik pada saat input kedua motor diberikan 150 Volt. Akan tetapi, pada saat input motor kisaran 100 Volt, sinkronisasi bisa dilakukan tetapi pembacaan alat masih tidak stabil yang disebabkan karena ketidakstabilan RPM.

\section{Output Sinkronisasi}

TABEL IV. HASIL PENGUJIAN SINKRONISASI

\begin{tabular}{|c|c|c|c|c|c|c|c|c|c|c|}
\hline \multirow[t]{2}{*}{ Vg1 } & \multirow[t]{2}{*}{ Vg2 } & \multicolumn{3}{|c|}{ Output } & \multicolumn{3}{|c|}{ G1 } & \multicolumn{3}{|c|}{ G2 } \\
\hline & & $\begin{array}{c}\mathbf{V}_{\mathbf{R}} \\
\mathbf{N}\end{array}$ & $\begin{array}{c}\text { Vs- } \\
\mathbf{N}\end{array}$ & $\begin{array}{c}\mathbf{V}_{\text {T- }} \\
\mathbf{N}\end{array}$ & $\begin{array}{c}\text { VR- }_{\text {- }} \\
\mathbf{N}\end{array}$ & $\begin{array}{c}\text { Vs- } \\
\text { N }\end{array}$ & $\begin{array}{c}\mathbf{V}_{\mathbf{T}-} \\
\mathbf{N}\end{array}$ & $\begin{array}{c}\mathbf{V}_{\mathbf{R}-} \\
\mathbf{N}\end{array}$ & $\begin{array}{c}\text { Vs- } \\
\text { N }\end{array}$ & $\begin{array}{c}\mathbf{V}_{\mathbf{T}} \\
\mathbf{N}\end{array}$ \\
\hline 50 & 50 & 55 & 54 & 52 & 50 & 49 & 47 & 50 & 47 & 48 \\
\hline 60 & 60 & 60 & 60 & 60 & 60 & 56 & 56 & 60 & 60 & 60 \\
\hline
\end{tabular}

Keterangan :

Vg1 = Tegangan generator 1 (pengukuran alat)

Vg2 = Tegangan generator 2 (pengukuran alat)

G1 = Generator 1

$$
\begin{array}{ll}
\mathrm{G} 2 & =\text { Generator } 2 \\
\mathrm{~V}_{\mathrm{R}-\mathrm{N}} & =\text { Tegangan fasa R-N } \\
\mathrm{V}_{\mathrm{S}-\mathrm{N}} & =\text { Tegangan fasa } \mathrm{S}-\mathrm{N} \\
\mathrm{V}_{\mathrm{T}-\mathrm{N}} & =\text { Tegangan fasa T-N } \\
\text { Output } & =\text { Output Sinkronisasi }
\end{array}
$$

Berdasarkan tabel 4, dapat dilihat terjadi kondisi unbalance pada tegangan antara kedua generator karena pengaruh overheating. Output dari sinkronisasi pun mengalami error atau tidak sesuai dengan yang diinginkan karena mungkin salah satu generator berubah menjadi beban karena memiliki kapasitansi berbeda. Adapun \% unbalance pada kedua generator sebagai berikut.

Generator 1 :

$$
\begin{aligned}
V_{\text {rata-rata }} & =\frac{(\text { Jumlah keseluruhan tegangan })}{3} \\
& =\frac{(50+49+47)}{3} \\
& =48,60 \\
V \% & =\frac{100 \% \times(\text { selisih voltage rata-rata })}{\text { Voltage Rata-rata }} \\
& =\frac{100 \% \times(50-48,60)}{48,60} \\
& =2,88 \%
\end{aligned}
$$

Generator 2 :

$$
\begin{aligned}
V_{\text {rata-rata }} & =\frac{(\text { Jumlah keseluruhan tegangan })}{3} \\
& =\frac{(50+47+48)}{3} \\
& =48,33 \\
V \% & =\frac{100 \% \times(\text { selisih voltage rata-rata })}{\text { Voltage Rata-rata }} \\
& =\frac{100 \% x(50-48,33)}{48,33} \\
& =3,45 \%
\end{aligned}
$$

Keterangan :

$\mathrm{V} \% \quad=$ Besar Unbalace antar fasa (\%)

$\mathrm{V}_{\text {rata-rata }}=$ Tegangan rata-rata dari ketiga fasa

\section{Penutup}

Berdasarkan hasil pengujian, dapat disimpulkan bahwa sinkronisasi generator dengan mikrokontroller ArduinoMega dapat dilakukan sesuai dengan apa yang diinginkan selama memenuhi syarat-syarat sinkronisasi terpenuhi. Pada pengujian terpisah, alat dapat berfungsi cukup baik dalam membaca nilai-nilai syarat sinkronisasi, walau memang masih terdapat error pada nilai tertentu karena bawaan range kemampuan pembacaan sensor. selain itu, pembacaan sensor masih didapati tidak stabil, salah satu kelemahannya adalah begitu terjadi sinkronisasi, nilai sensor berubah menjadi tidak stabil karena sensor tidak bisa membaca nilai syarat kembali 
setelah terjadi sinkronisasi. Berikutnya, juga terjadi keadaan noise pada konduktor alat.

Dari pengujian, hasil dari output sinkronisasi tidak sesuai dengan yang diinginkan walaupun syarat sinkronisasi sudah terpenuhi dan sinkronisasi dijalankan. Berdasarkan teori, output dari sinkronisasi harusnya menghasilkan tegangan yang nilainya lebih besar dari gabungan output kedua generator. Hal ini terjadi karena reverse power atau salah satu generator menjadi beban (motor) pada generator lainnya. Selain itu, saat sinkronisasi dilakukan, beberapa kali terjadi kegagalan karena RPM dan frekuensi kedua generator berbeda karena tidak stabil.

\section{REFERENSI}

[1] S. Ardhi, "Pengendalian Sinkronisasi Generator dengan Sumber Pembangkit Listrik Secara Otomatis Berbasis Mikrokontroller," vol. 7, no. 1, pp. 36-42, 2015.

[2] Hardianto, "Kajian Sistem Sinkronisasi Generator Pada Beban 3 Phase Study of Generator Synchronization System in 3 Phase," SEMINASTIKA, 2018.

[3] M. T. Agiantoro, Gellen Twin., Prasetyo, "Sinkronisasi Generator 3 Phase dengan Kapasitas Daya 511 KVA dan 820 KVA yang Berbeban di PT Ungaran Sari Garments," pp. 37-41, 2018.

[4] S. J. Chapman, Electric Machinery and Power System Fundamentals. Australia: MC GrawHill Book Company, 2004.

[5] M. A. Assyidiq, B. Winardi, and T. Andromeda, "Perancangan Boost Converter Menggunakan Voltage Feedback Pada Panel Surya," Transient, vol. 6, no. 3, p. 404, 2017, doi: 10.14710/transient.6.3.404-410.

[6] Fathurachman, Ahmad., Najmurrokhman, Asep., and Kusnandar, “Perancangan Boost Converter Untuk Sistem Pembangkit," Batara Pilar Tek., 2016.

[7] I. Irkham, I. Setiawan, and A. Nugroho, "Perancangan Boost Converter Sebagai Suplai Inverter Menggunakan Dspic30F4011 Dengan Metode Kontrol Proportional Integral," Transient, vol. 7, no. 3, p. 737, 2019, doi: 10.14710/transient.7.3.737-744.

[8] S. Budiyanto, "Sistem Logger Suhu dengan Menggunakan Komunikasi Gelombang Radio," Teknol. Elektro, vol. 3 no.1, pp. 2127, 2012.

[9] Taufiq Alif Kurniawan, Optimasi Rangkaian Detektor Fasa Frekuensi Rendah sebagai Rangkaian Pembaca Kelauran Sensor Kelembaban dan Konduktivitas Elektrik. Depok, 2009.

[10] T. P. F., Y. C. A., and Suhariningsih, "Sinkronisasi Dan Pengamanan Modul Generator Lab-Tst,” pp. 1-6, 2011.

\section{BIODATA PENULIS}

Atika Endefi, lahir di Payakumbuh, 2 Mei 1998. Sedang Menyelesaikan Studi Teknik Elektro Industri (DIV), di Jurusan Teknik Elektro Fakultas Teknik Universitas Negeri Padang dengan tahun masuk 2016.

Dr. Sukardi, M.T, dilahirkan di Semerap Kerinci, 10 Mei 1961. Adalah dosen aktif di jurusan Teknik Elektro Fakultas Teknik Universitas Negeri Padang, yangmana beliau sekarang menjabat sebagai Kepala Pusat Program Pengalaman Lapangan. Riwayat pendidikan beliau dengan Sarjana 1 di IKIP Padang, Magister di Insititut Teknologi Bandung dan Doktor di Universitas Negeri Yogyakarta. 